\title{
Zur Entwicklung und zum Gegenstandbereich der deutschen und der polnischen Phraseologie
}

\author{
Jolanta Ignatowicz-Skowrońska und Anna Sulikowska (Stettin)
}

\begin{abstract}
The aim of the article, which is addressed to a German reader with phraseological interests, is the depiction of research development within phraseology and terminological agreements in the tradition of phraseology in Polish and German. In the centre of our interest remains the definition of the term phraseme, specification and description of the phraseme features in the context of the contemporary research and also attempts concerning phraseme classifications.
\end{abstract}

\section{Zur Forschungsgeschichte der deutschen und der polnischen Phraseologie}

\subsection{Die vorwissenschaftliche Phase: Phraseologismen in deutschen und polnischen Wörterbüchern}

Den wissenschaftlichen Erwägungen zum Wesen der Phraseologismen sind - sowohl in Polen als auch in Deutschland - Jahrhunderte vorausgegangen, in denen man sich mit ihnen implizit befasste. Die Existenz der festen Mehrwortverbindungen, des Öfteren von einem metaphorischen Charakter, wurde nämlich schnell von Lexikographen wahrgenommen, die sie gerne, wenngleich nicht konsequent und auf der Grundlage intuitiver Kriterien, in ihre Werke aufgenommen haben. Auf das Vorkommen der vorwissenschaftlichen Phase in der polnischen Phraseologie verweist Skorupka (1988: 7) und in der deutschen Phraseologie Burger (2007b: $620)$.

Skorupka (1988: 7-14) hat in seinen Überlegungen zur Auffassung der Phraseologismen in der polnischen Lexikographie eine Periodisierung der Untersuchungen vorgenommen. Dementsprechend wurden zwei Phasen differenziert: die Periode der phraseologischen Praxis und die Periode der phraseologischen Theorie. Die Anfänge der Periode der phraseologischen Praxis reichen in das 15 . und 16. Jh. zurück und beruhen auf der lexikographischen Registrierung von festen Wortverbindungen zuerst in den Übersetzungswörterbüchern, dann ebenfalls in den einsprachigen Nachschlagewerken. Einzelne feste Wendungen finden wir also in den ältesten lexikographischen Sprachdenkmälern (vgl. Skorupka 1988: 7; Żmigrodzki 2003: 123), während sie in den für das 16., 17. und 18. Jh. repräsentativen Wörterbüchern von Jan Mączyński, Grzegorz Knapski und Michał Abraham Trotz schon in größerer Anzahl und Mannigfaltigkeit vorkommen. Diese Praxis wurde im 19. Jh. ebenfalls von den Autoren der einsprachigen Wörterbücher aufgegriffen, in dieser Zeit erscheinen die ersten Veröffentlichungen, die den Phraseologismen einen besonderen Stellenwert einräumen. Beachtenswert 
ist hier vor allem das monumentale, in Handschrift erhalten gebliebene Werk von Alojzy Osiński (1807) Bogactwa mowy polskiej ('Reichtümer der polnischen Sprache'), das ursprünglich - wie es aus der Lektüre der veröffentlichten Textabschnitte folgt - als ein eigentümliches stilistisch-phraseologisches Wörterbuch konzipiert wurde.

Ein anderes Werk bildet Księga przysłów, przypowieści $i$ wyrażeń przysłowiowych polskich ('Buch der polnischen Sprichwörter, Parabeln und sprichwörtlichen Redensarten') von Samuel Adalberg (1894), bei dessen Bearbeitung der Autor fast 100000 Wortverbindungen gesammelt, endgültig aber nur 30000 das Kriterium des Sprichwortes erfüllende Einheiten in die Sammlung aufgenommen hat. Dazu schreibt Skorupka (1988: 11): "Es ist schade, dass er nicht das ganze Material veröffentlicht hat, weil dies wahrscheinlich das erste umfangreiche phraseologische Großwörterbuch gewesen wäre." Im Endergebnis hat das verhältnismäßig bescheidene Słowniczek frazeologiczny. Poradnik dla piszacych ('Phraseologisches Taschenwörterbuch. Ein Ratgeber für Schreibende') von Antoni Krasnowolski (1899) als erstes phraseologisches Wörterbuch Eingang in die Geschichte der polnischen Lexikographie gefunden.

Die vor vielen Jahren in die Wege geleitete Periode der phraseologischen Praxis dauert bis heute und bringt immer mehr phraseologische Publikationen. Während bis 1989 außer der historischen Sammlung Krasnowolskis nur ein einziges umfassendes phraseologisches Wörterbuch von Skorupka zur Verfügung stand, sind nach 1989 zahlreiche weitere Nachschlagewerke erschienen. Gabriela Dziamska-Lenart (2010: 178) schätzte 2010, es gebe auf dem Markt über 30 Wörterbücher, wobei zu den größten Popularny słownik frazeologiczny ('Populäres phraseologisches Wörterbuch') von Katarzyna Głowińska (2000), Słownik frazeologiczny wspótczesnej polszczyzny ('Phraseologisches Wörterbuch der polnischen Gegenwartssprache') von Stanisław Bąba und Jarosław Liberek (2001), Wielki słownik frazeologiczny języka polskiego ('Phraseologisches Großwörterbuch der polnischen Sprache') von Piotr Müldner-Nieckowski (2003) sowie das von einem Autorenkolleg (Kłosińska/Sobol/Stankiewicz) 2005 herausgegebene Wielki słownik frazeologiczny PWN z przystowiami ('Phraseologisches Großwörterbuch mit Sprichwörtern') gehören. Hervorzuheben ist dabei die methodologische Entwicklung der Wörterbücher: Die Aufnahme der Phraseologismen war zu Beginn von fast keiner methodologischen Reflexion begleitet, erst ab dem 19. Jh. tauchen in den Lexika Bemerkungen zu dieser Problematik auf. Eine besondere Bedeutung für die Aussonderung und Registrierung von festen Wortverbindungen ist dabei den Erwägungen von Witold Doroszewski (1954, 1958), Stanisław Skorupka (1967: 5-11), später Andrzej Maria Lewicki, Anna Pajdzińska und Bożena Rejakowa (1987), Andrzej Bogusławski (1989: 13-30), Stanisław Bąba, Jarosław Liberek und Gabriela Dziamska (Bąba/Liberek 1992; Bąba/Dziamska/Liberek 1995; Bąba/Liberek 2001), Mirosław Bańko (2001: 149-187) sowie Piotr Müldner-Nieckowski (2007) einzuräumen. Diese Arbeiten haben zur Konstituierung einer neuen sprachwissenschaftlichen Disziplin - Phraseographie - beigetragen, die heutzutage auch beachtliche Leistungen auf dem Gebiet der Metaphraseographie aufweisen kann.

$\mathrm{Zu}$ Beginn entwickelte sich die Periode der phraseologischen Praxis in Deutschland auf eine ähnliche Weise. Erste Beispiele der deutschen Phraseologismen sind in den lateinischdeutschen oder in den lateinisch-griechisch-deutschen Übersetzungswörterbüchern aus dem 16. Jh. verzeichnet worden, vgl. Der sog. Große Fries, das Dictionarium Latinogermanicum von Johannes Frisius (1556), Lexicon trilingue von Schelling/Emmel (1586) (vgl. Mül- 
ler/Kunkel-Razum 2007: 940). Einen wesentlichen Einfluss auf die deutsche Phraseologie in der vorwissenschaftlichen Phase hatte dennoch ebenfalls die Sprichwörterlexikographie, deren Wurzeln nicht so sehr in linguistischen, sondern vielmehr in kulturell-pädagogischen Interessen liegen. Die Sprichwörtersammlungen wurden also zur "Pflege vaterländischer Sprachkenntnis in der Volksschule" (vgl. Deutsche Redensarten: Zur Pflege vaterländischer Sprachkenntnis in der Volkshochschule hrsg. von Wunderlich 1886), "für gebildete Leser, die sich freuen Deutsche zu sein und die unsre prächtige Sprache lieb haben" (Schrader 1894, X) geschaffen sowie, wie in seiner Vorrede Karl Friedrich Wilhelm, der Autor eines monumentalen, über 250000 Stichwörter zählenden Wörterbuches Deutsches Sprichwörter-Lexikon erläutert:

... weil sie [die Sprichwörter] die Farbe und den Charakter des Volkes an sich tragen und die Kenntnis von dessen Sitten und Gebräuchen, wie von dessen Art zu sehen und zu fühlen geben; wie sie nur die Art und Weise enthüllen, wie die Völker anschauen und Denken, während die Geschichte uns mehr die äussern Beziehungen eines Volkes zeigt und sich mehr mit dem Charakter der Privatpersonen und ihres Einflusses auf die Nation beschäftigt.

(Wander 1867, V)

Schon in der ersten Sprichwörtersammlung von Johann Agricola (1529) wurden sog. sprichwörtliche Redensarten (metaphoricae phrases) aufgeführt. Sprichwörter und sprichwörtliche Redensarten registrierte man ebenfalls später zusammen in den Wörterbüchern und Lexika, manche Autoren (z. B. Wander 1867-1880) nahmen dabei einen Versuch vor, sie auseinanderzuhalten, andere (z. B. Eiselein 1840) nicht (vgl. Burger 2007b: 620). Eine konsequente, wissenschaftliche Differenzierung erfolgte erst in der 2. Hälfte des 20. Jhs. mit der Veröffentlichung von zwei wichtigen allgemeinen Wörterbüchern: des in der BRD von Dudenredaktion herausgegebenen sechsbändigen Großen Wörterbuches der Deutschen Sprache (GWDS, 1976-1981) und des zweibändigen in der DDR 1984 publizierten Handwörterbuches der Deutschen Sprache (HDG). In beiden Werken wurden die Phraseologismen im Vorwort theoretisch explizit behandelt und im alphabetischen Teil gesondert dargestellt (vgl. Müller/Kunkel-Razum 2007: 942-943).

Zu dieser Zeit erscheinen auf dem Markt ebenfalls die ersten phraseologischen Wörterbücher: 1000 idiomatische Redensarten Deutsch von Schulz/Griesbach (1961), Moderne deutsche Idiomatik von Wolf Friederich (1966), Das große Lexikon von sprichwörtlichen Redensarten von Lutz Röhrich (1973), Zitate, Redensarten, Sprichwörter von Lutz Mackensen (1973), der von Drosdowski/Scholze-Stubenrecht bearbeitete Dudenband 11 (1992) sowie die Deutsche Idiomatik von Hans Schemann (1993) (vgl. Müller/Kunkel-Razum 2007: 945).

\subsection{Die Entwicklung der Phraseologie als einer wissenschaftlichen Disziplin}

Eine wesentlich kürzere Geschichte hat in beiden Ländern die Periode der phraseologischen Theorie. Die ersten vorwissenschaftlichen Reflexionen über das Wesen der Phraseologismen wurden in Polen um die Wende des 19. und 20. Jhs. angestellt, wovon die Arbeiten von Krasnowolski (1899; 1905-1906), Stanisław Szober (1937: 93-96; 1939: 50-65) und Tadeusz Sinko (1939) zeugen. Als Wissenschaft konstituiert sich dennoch die Phraseologie in Polen erst in den 50er Jahren des 20. Jhs. und als ihr Begründer wird Stanisław Skorupka angesehen. Skorupka (1952b ) hat als erster die Begriffe Phraseologismus und Phraseologie definiert, die Phraseologie von anderen sprachwissenschaftlichen Disziplinen abgesondert (vgl. 
ebd. 1952a, 1958a, 1960) sowie eine Klassifikation der Phraseologismen vorgenommen (vgl. ebd. 1969, 1982). Darüber hinaus befasste er sich u. a. mit der phraseologischen Variabilität (vgl. ebd. 1986) und Korrektheit (vgl. ebd. 1950a, 1951, 1968b), mit der Funktion und Genese der lexikalisierten Mehrwortverbindungen (vgl. ebd. 1950b, 1972, 1973), mit der phraseologischen Struktur slawischer Sprachen (vgl. ebd. 1965, 1973) sowie mit der Phraseodidaktik (vgl. ebd. 1958b, 1968a).

Die phraseologischen Ansichten Skorupkas bildeten sich dabei unter dem Einfluss der Pioniere der europäischen Phraseologie - Bally und Winogradov - heraus. Dies kommt sowohl in der Definition- und Klassifikationsweise der phraseologischen Spracheinheiten zum Ausdruck, als auch in seiner weiten Auffassung der Phraseologismen, zu denen er nicht nur stabile, sondern auch kombinierbare und lose Wortverbindungen (zwiazki frazeologiczne stałe, taczliwe, luźne) sowie Sprichwörter zählte. Die phraseologische Theorie Skorupkas wird heutzutage für klassisch gehalten und als solche auch in den Schul- und Hochschullehrbüchern (vgl. Kania/Tokarski 1984; Markowski 2012; Krawczuk 2011) aufgeführt, wenngleich der wissenschaftliche Diskurs auf neuere Vorschläge Bezug nimmt. Ein besonderer Stellenwert kommt dabei den Ansichten des Lubliner Forschers Andrzej Maria Lewickis zu, der die Phraseologie einerseits auf stabile und kombinierbare Wortverbindungen einschränkt, andererseits auf ihren relativen Charakter verweist. Im Zentrum seines Interesses befinden sich die Theorie der phraseologischen Wortverbindung (vgl. Lewicki 1976), das Problem der Phraseologiezitätskriterien (vgl. ebd. 1986, 1992), die Typologie der phraseologischen Wortverbindungen (vgl. ebd. 1986, 1992), die phraseologischen Varianten (vgl. ebd. 1982: 427-435; 1973), phraseologische Derivation (vgl. ebd. 1981, 1994), Motivation (vgl. ebd. 1982, 1985, 1990) und Genese (vgl. ebd. 1986).

Eine weitere Betrachtungsperspektive stellt Chlebda $^{1}$ wieder, der dabei eine Variante der Phraseologie begründete, die er die Phrasematik nannte. Phraseme hat Chlebda (1991: 26) als sprachliche Einheiten definiert, die "in einer bestimmten Situation zur Benennung eines Inhaltspotentials von dem Sprechenden reproduziert und nicht aus ad hoc gewählten, nacheinander folgenden Elementen produziert werden".

Gleichzeitig mit der Definition der grundlegenden Termini, der Festlegung der Grenzen von der sich konstituierenden neuen Wissenschaftsdisziplin und der Klassifizierung der phraseologischen Spracheinheiten vollzog sich in der polnischen Phraseologie eine vielseitige und vertiefte Beschreibung des korrekten Gebrauchs und der Funktionsweise der festen Wortverbindungen in verschiedenen Textsorten. Eine Theorie der sprachlichen Richtigkeit im Rahmen der Phraseologie hat ein Posener Sprachwissenschaftler - Stanisław Bąba - erarbeitet, der in Anlehnung an die Konzeption der sprachlichen Norm von Halina Kurkowska die Begriffe der phraseologischen Norm, Modifikation und des phraseologischen Fehlers präzisiert sowie die Klassifikation der phraseologischen Modifikationen und die Prinzipien der phraseologischen Richtigkeit bearbeitet (Bąba 1979, 1989). Zahlreiche Texte widmete man des Weiteren dem Funktionieren von Phraseologismen in der Literatur, Presse und Werbung, den biblischen Phraseologismen, sowie der regionalen, dialektalen, Fach- und Kontrastivphraseologie, während neuere Untersuchungen deutlich durch kognitive Methodologie geprägt sind.

\footnotetext{
${ }^{1}$ Chlebda gilt ebenfalls als ein hervorragender Forscher der geflügelten Worte, denen er zahlreiche Artikel und eine Monographie Szkice o skrzydlatych słowach ('Skizzen über geflügelte Worte') (2005) gewidmet hat.
}

ISSN 1615-3014 
Den Umfang und den Fortschritt des Forschungsstandes der polnischen Phraseologie stellen eindeutig die von Bąba gesammelten Materiaty do bibliografii frazeologii polskiej ('Materialien zur Bibliographie der polnischen Phraseologie') dar. In den bis heute erschienenen drei Teilen $(1998,2003,2008)$ dieser Veröffentlichung werden 1545 thematisch geordnete Arbeiten aus den Jahren 1945-2005 aufgeführt.

Die Konstituierung der Phraseologie als eines Forschungsbereiches der Sprachwissenschaft erfolgte in Deutschland zwei Jahrzehnte später als in Polen. Die erste wesentliche Anregung kam dabei Anfang der 70er Jahre aus der sog. Auslandsgermanistik. Eine sowjetische Forscherin - Irina Černyševa - (1970) verwies auf eine Lücke in der Erforschung von festen Mehrwortverbindungen in der deutschen Sprache und schlug in Anlehnung an die bereits etablierten Festlegungen der slawischen Phraseologie die Definition grundlegender Termini, Ziele und Desiderate der neuen Disziplin vor (vgl. Fleischer 1982: 24; Burger 2007b: 621). Ein Jahr später wurde die Doktorarbeit von Ulla Fix veröffentlicht (1971) und im Jahre 1973 erschien unter dem Titel Idiomatik des Deutschen die erste Einführung in die deutsche Phraseologie von Harald Burger. Seit dieser Zeit steigt die Anzahl der Publikationen über die festen Mehrwortverbindungen lawinenartig.

Die Anfangsphase der Entwicklung der deutschen Phraseologie ist durch Versuche der Definition und der Klassifikation der Phraseologismen gekennzeichnet (vgl. z. B. Burger 1973, Rothkegel 1973, Häusermann 1977, Jaksche/Sialm/Burger 1981), die zu Auseinandersetzungen zu dem Geltungsbereich des Terminus Phraseologismus und der Herausbildung einer äußerst uneinheitlichen, die Kommunikation erschwerenden Terminologie geführt haben (vgl. Burger 2007b: 621). Der inzwischen etablierte Begriff Phraseologismus wurde beispielshalber ebenfalls als Floskel, Fügung, Phraseolexem, Redensart, Redewendung, Stereotyp, Sprachformel, Schematismus, Wortverbindung, Verbindung, Wortfügung, Wortgefüge, Wendung bezeichnet. Einen wichtigen Wendepunkt führte erst die Veröffentlichung der Monographie von Wolfgang Fleischer Phraseologie der deutschen Gegenwartssprache (1982) sowie des von Burger u. a. herausgegebenen Handbuches der Phraseologie (1982) herbei, deren Autoren die Vereinheitlichung der Stellungen und der Terminologie anstrebten. In diesen Arbeiten wird folglich eine flexible Definition angenommen und der Begriff Phraseologismus als ein Hyperonym für eine heterogene Klasse fester Wortverbindungen akzeptiert. Der Einfluss der erwähnten Publikationen auf die Herausbildung der germanistischen Phraseologie war so groß, dass Burger (2007b: 619) ihre Geschichte in drei Entwicklungsphasen einteilt: die vorwissenschaftliche Phrase, die sich von der Veröffentlichung Černyševas bis zu den Publikationen von Burger und Fleischer erstreckende Anfangsphase (1970-1982) und die gegenwärtige Konsolidierungsphase.

Dementsprechend setzt sich ab der ersten Hälfte der 80er Jahren des 20. Jhs. die Ansicht durch, dass eindeutige Kategorisierung und Klassifizierung der Phraseologismen nicht möglich ist und Grenzfälle zur Natur der Phraseologie gehören. In den Mittelpunkt des wissenschaftlichen Interesses werden dafür interdisziplinäre Aspekte gerückt: Intensiv entwickeln sich die Phraseopragmatik, Phraseographie, Phraseodidaktik, Untersuchungen zu den kognitiven und psycholinguistischen Aspekten der Phraseologismen und ihrer Repräsentation im mentalen Lexikon sowie die kontrastive Phraseologie. 


\section{Merkmale der Phraseologizität und Definition}

Ähnlich wie in Deutschland ist es der polnischen Phraseologie nicht gelungen, den terminologischen Problemen auszuweichen. Am frühesten machte darauf Skorupka (1952b) aufmerksam, dann Chlebda (2001: 179), was folgende Worte vor Augen führen: "Die größte Schwierigkeit scheint in der uneinheitlichen Auffassung des Begriffes Phraseologismus und im Resultat - in der Unentschiedenheit zu den Grenzen der Phraseologie zu liegen."2 Der Forscher weist auf die allgemeine Einstimmigkeit hin, mit der semantisch unregelmäßige Wortverbindungen wie biały kruk ('weißer Rabe'), wieża Babel ('Turm zu Babel'), działać na kogoś jak czerwona płachta na byka ('wie ein rotes Tuch auf jmdn. wirken') zu den Phraseologismen gezählt werden, während man andere, über diesen Kanon hinausgehende feste Mehrwortverbindungen: phraseologische Fachtermini ${ }^{3}$ (z. B. trójkąt równoramienny 'gleichschenkliges Dreieck'), onymische Phraseologismen (z. B. Daleki Wschód 'Ferner Osten'), Sprichwörter (z. B. Niedaleko pada jabłko od jabłoni 'Der Apfel fällt nicht weit von Stamm') unterschiedlich behandelt: Manche Forscher ziehen sie in den Bereich der Phraseologie ein, andere schließen sie aus (vgl. Chlebda 2001: 179). Von Relevanz sind ebenfalls die Bemerkungen von Andrzej Bogusławski (1989: 19), dem Befürworter einer weiten Auffassung der Phraseologie, der die Hypothese aufstellt, die Mehrwortverbindungen (Phraseologismen) seien in der Sprache "sicher unvergleichbar zahlreicher als Einworteinheiten - ihre Zahl beläuft sich auf viele Millionen, während Einworteinheiten sogar bei der Bedeutungsspaltung eher eine Hunderttausende zählende Gruppe bilden"4. Damit widersetzt er sich der geläufigen Meinung, die Phraseologie spiele in der Sprache lediglich eine marginale, ornamentale Rolle.

Der Phraseologismus kann also nicht definiert werden, ohne dass man seine charakteristischen Merkmale ausdifferenziert. Die Übersicht über die Fachliteratur lässt Bogusławski (1989) 12 Merkmale unterscheiden, die traditionellerweise den Mehrwortverbindungen vom Typ: nie wylewać kolnierz ( $\approx$ 'sich gern einen hinter die Binde kippen') zugeschrieben werden. Das sind: (1) Reproduktivität (odtwarzalność): die Wortverbindung wird als Ganzes reproduziert und nicht ad hoc aus dem lexikalischen Material unter dem Einsatz produktiver Sprachregeln gebildet; (2) große Frequenz (duża frekwencja) des Auftretens von diesen Wortverbindungen; (3) graphischer Mehrwortcharakter (wielowyrazowość graficzna): ein Ausdruck stellt eine Reihe von mehr als einem graphischen Wort dar; (4) phonologischer Mehrwortcharakter (wielowyrazowość fonologiczna): ein Ausdruck weist wenigstens zwei Akzente auf; (5) Diskontinuierlichkeit/Teilbarkeit (nieciagłość): der Ausdruck ist in Teile zerlegbar, zwischen die andere Wortreihen korrekt eingefügt werden können; (6) unganzheitliche Flexion (nieglobalna fleksja): Flexionseigenschaften werden nicht dem ganzen Ausdruck, sondern seinen Konstituenten zugeschrieben; (7) Nonkompositionalität der Bedeutung (asumaryczność znaczenia): die Bedeutung ist der ganzen Wortverbindung zugeschrieben und ergibt sich nicht aus der Summe ihrer Elemente; (8) die nach Bogusławski (ebd.) schwer zu definierende Bildlich-

\footnotetext{
2 "Trudnością najważniejszą wydaje się niejednoznaczność rozumienia samego pojęcia "frazeologizm" i w rezultacie - niezdecydowanie co do granic frazeologii językowej" (Chlebda 2001: 179).

${ }^{3}$ Vgl. 'zusammengesetzte Termini und Terminologismen' (terminy złożone i terminologizmy) bei Chlebda (2005: $83)$.

${ }^{4}$ Wielowyrazowców jest "na pewno bez porównania więcej niż jednostek jednowyrazowych - idą one jawnie w grube miliony, podczas gdy jednowyrazowce nawet przy rozszczepieniu znaczeniowym tworzą raczej grupę rzędu setek tysięcy" (Bogusławski 1989: 19).
}

ISSN 1615-3014 
keit (obrazowość), die mit der Fähigkeit vieler Phraseologismen zur Evozierung von mentalen Bildern verbunden ist; (9) Expressivität (ekspresywność): die der Neutralität gegenüberstehende expressiv-stilistische Kennzeichnung; (10) syntaktische Unvollständigkeit (niepetność zdaniowa): Phraseologismen fungieren nicht als vollständige grammatische Einheiten (d. h. Sätze), sondern als Funktoren, die erst in Verbindung mit anderen Ausdrücken Sätze bilden können; (11) syntaktische Unvollständigkeit im logischen Sinne (niepetność zdaniowa w sensie logicznym): fehlende Referenz zu einem Objekt; (12) elementare Komponentabilität (elementarna składnikowość): der Status einer sprachlichen Einheit und nicht eines Produktes der Sprache (ebd.: 13-15). Bogusławski setzt dabei voraus, dass nur der Mehrwortcharakter und elementare Komponentabilität zu den obligatorischen Merkmalen des Phraseologismus gehören (ebd.: 18). Das weitere Merkmal - die Reproduktivität des Phraseologismus - ergibt sich automatisch aus der Berücksichtigung der elementaren Komponentabilität.

Dem vorliegenden Beitrag wird die phraseologische Konzeption von Lewicki zugrundegelegt, der zusammen mit Pajdzińska (Lewicki/Pajdzińska 2001: 315) in einer allgemein zugänglichen Veröffentlichung von einem enzyklopädischen Charakter die Phraseologismen als "sozial konventionalisierte Wortverbindungen, die in einer Hinsicht Irregularität aufweisen" ${ }^{5}$, definiert. Diese Definition betont die bereits besprochenen Merkmale der "typischen" Phraseologismen wie ihr Mehrwortcharakter und Reproduktivität und bereichert sie um ein zusätzliches Merkmal - die weit aufgefasste Irregularität. Eine der möglichen Erscheinungsformen der Irregulatität - die Nonkompositionalität der Bedeutung - wurde bereits besprochen. Die phraseologische Irregularität kann aber auch auf der Formebene in der Gestalt der lexikalen, Flexions-, Wortbildungs- oder syntaktischen Archaismen zum Vorschein kommen (vgl. Bąba 1989: 12-20; Borejszo 1985: 341-349).

Bei der Analyse der typischen phraseologischen Einheiten hat Lewicki (1983: 75) in einem anderen Beitrag festgestellt, dass die Phraseologismen wenigstens zwei der drei Phraseologizitätskriterien erfüllen müssen: Sie sind nämlich (a) Verbindungen von wenigstens zwei betonten Segmenten, (b) Verbindungen von den mit Wörtern gleichgesetzten Komponenten, deren Gestalt mit den Lexemformen identifiziert wird, die auf eine für Wortgruppen charakteristische Weise miteinander verbunden sind, (c) durch die Diskontinuierlichkeit gekennzeichnet (d. h. die Komponenten eines Sprachzeichens können in unfesten Positionen auftreten, verschoben bzw. durch eingeschobene Elemente aufgeteilt werden). Bezeichnenderweise müssen die typologischen Merkmale der Phraseologismen "nicht in jeder zu den Phraseologismen zählenden Einheit realisiert werden"6 (Lewicki 1983: 76), in extremen Fällen werden kraft der Tradition oder der arbiträren Entscheidung des Lexikographen die Einheiten zur Phraseologie gezählt, die keinem der genannten Kriterien gerecht werden (vgl. hokus pokus 'Hokuspokus', od dawna 'seit langem').

Im Gegensatz zu der relativen Auffassung der Phraseologismen in der polnischen Sprachwissenschaft und deutlichen Differenzen in der von verschiedenen Forschern angenommenen Anzahl der phraseologischen Merkmalen besteht in der germanistischen Fachliteratur heutzutage ein weitgehender Konsens über die Beschreibung der Phraseologismen unter der Voraus-

\footnotetext{
5 "społecznie utrwalone połączenia wyrazów wykazujące nieregularność pod jakimś względem" (Lewicki 2001: 316).

6 "nie muszą być realizowane w każdej jednostce zaliczanej do związków frazeologicznych" (Lewicki 1983: 76).
} 
setzung von drei grundlegenden Merkmalen: der Polylexikalität, der Festigkeit ${ }^{7}$ sowie der Idiomatizität (vgl. Fleischer 1982, 1997; Wotjak 1992; Donalies 1994; Palm 1995; Burger 2010).

Das Merkmal der Polylexikalität (Mehrgliedrigkeit) ist von struktureller Natur und bezieht sich auf den Zwei- oder Mehrwortcharakter der phraseologischen Wortverbindung. Dieses auf den ersten Blick als unproblematisch erscheinende Kriterium bereitet in der Praxis manchmal Schwierigkeiten und bedarf individueller Entscheidungen. Umstritten ist dabei sowohl die obere als auch die untere Grenze der Phraseologie. So verleiht Burger (2010: 37) den sog. strukturellen Phraseologismen ${ }^{8}$ (weder ... noch, entweder ... oder, sowohl ... als auch, so dass) den Status einer phraseologischen Klasse, während Fleischer (1982: 72) das Kriterium der Polylexikalität auf Wortverbindungen mit wenigstens einem Autosemantikon einschränkt. Als die etablierte obere Grenze der Phraseologie wird der Satz angesehen, womit Sprichwörter, Antisprichwörter, Wellerismen, geflügelte Worte als Gegenstandsbereich der Phraseologie gelten (vgl. Burger u. a. 2007a; Burger 2010; Donalis 1994; Hessky 1992, 2000; Palm 1995), unter dem Einfluss der Pragma- und Textlinguistik wird dennoch in den letzten Jahren ein immer größeres Interesse auf Phraseotexteme (z. B. Zu Risiken und Nebenwirkungen lesen Sie die Packungsbeilage und fragen Ihren Arzt oder Apotheker) sowie formelhafte/phraseologische Texte (z. B. Todesanzeigen, Danksagungen, Ansagen der Lottozahlen) gerichtet (Dausendschön-Gay/Gülich/Krafft 2007; Stein 2011).

Die Festigkeit beruht darauf, dass die Phraseologismen im Gegensatz zu freien Wortverbindungen auf der paradigmatischen Ebene nicht substituierbar sind (mit einem blauen Auge davon kommen, aber *mit einem blauen Äuglein davonkommen) und ihre Kombinierbarkeit auf syntagmatischer Ebene eingeschränkt ist. Vor dem Hintergrund der neuesten Korpusuntersuchungen wird dennoch betont (vgl. Burger 2010: 29; Dobrovol'skij 1997: 71; Hümmer 2009: 83; Burger 2007b: 623), das die Festigkeit kein absolutes, sondern ein relatives Kriterium darstellt: Die Variationen (keinen Finger rühren/krumm machen/regen; jmdm. fällt die/eine Binde von den Augen, auf/unter den Nägeln brennen, weder aus noch ein wissen/nicht aus und ein wissen, Daumen/Däumchen drehen) und Modifikationen ${ }^{9}$ sind nämlich im authentischen Sprachgebrauch weit mehr verbreitet als man früher angenommen hat und die absolute Stabilität trifft auf eine kleine Phraseologismengruppe zu (vgl. Burger 2010: 25). Mit dem Begriff der Festigkeit sind weitere Termini eng verbunden, die dieses Phänomen aus anderen Betrachtungsperspektiven beschreiben. Somit unterstreicht Reproduzierbarkeit, dass Phraseologismen aus dem mentalen Lexikon als fertige Spracheinheiten abberufen und nicht wie freie Wortverbindungen in jeder konkreten Äußerung ad hoc unter Einbezug der Sprachregeln und des Lexikons generiert werden (vgl. Dobrovol'skij 1995). Den Lexikonstatus (Idiome als long words) vieler opaken Phraseologismen (z. B. ins Gras beißen) betont ebenfalls der Begriff der Lexikalisierung (vgl. Burger 1982).

\footnotetext{
${ }^{7}$ Bei Fleischer (1997) als "Stabilität" bezeichnet.

${ }^{8}$ Zur Definition von strukturellen Phraseologismen vgl. die Klassifikation der Phraseologismen in diesem Beitrag.

${ }^{9}$ Hümmer (2009: 248-249) veranschaulicht beispielshalber aufgrund einer detaillierten Korpusanalyse, dass Modifikationen des Idioms $j d$. ist mit allen Wassern gewaschen in 36\% von 548 Belegen auftreten, im Falle des Idioms $j d$. schüttelt etw. aus dem Ärmel sind es 14\% und bei Idiom jmd. hat es faustdick hinter den Ohren 6\%.
} 
Das letzte Kriterium der Idiomatizität weist deutliche Parallelen zum Kriterium der Nonkompositionalität bei Bogusławski auf. Idiomatizität bedeutet, dass die phraseologische Bedeutung sich nicht regulär (oder nur partiell regulär) aus den freien Bedeutungen der Komponenten ableiten lässt (vgl. Burger 2010: 32). Idiomatizität kann dabei aus der Perspektive der Sprachproduktion (Enkodierung), wo sie als eine Einschränkung der Freiheit des Sprechers bezüglich der Kombinatorik sprachlicher Zeichen, oder aus der Perspektive der Dekodierung - als Unableitbarkeit der Gesamtbedeutung des Idioms aus den Bedeutungen seiner Komponenten - aufgefasst und beschrieben werden (vgl. Hümmer 2009: 78-82). Idiomatizität stellt eine radiale Kategorie dar und umfasst sowohl stark idiomatische Einheiten mit einer opaken Semantik (den Löffel abgeben 'sterben') als auch zahlreiche motivierte Idiome (jmdn. in die Zange nehmen 'jmdn. hart unter Druck setzen, jmdn. bedrängen'), in denen die Bedeutung der Komponenten nicht gänzlich verschwunden, sondern "in unterschiedlicher Weise an der Verwendung des Ausdrucks beteiligt ist" (Burger 2010: 59). Einen interessanten Versuch der Parametrisierung von Idiomatizität nimmt Dimitrij Dobrovol'skij (1995: 27-44) vor, der zur Festlegung des Zentrum und der Peripherie der Idiomatik 12 Irregularitätsindizien ausdifferenziert: (1) Kompositionalität vs. Nonkompositionalität der Bedeutung; (2) Isomorphie vs. Allomorphie zwischen der formalen und semantischen Struktur; (3) Semantische Komplexität vs. semantische Simplizität; (4) Syntaktische Durchlässigkeit vs. Undurchlässigkeit; (5) Variabilität vs. Fixiertheit des Konstituentenbestandes; (6) Konnotativ-pragmatische Extension der Idiombedeutung: neutral vs. markiert; (7) Formale Spezifikation: neutral vs. markiert; (8) Konstituentenbestand: konventionelle Lexikoneinheiten vs. unikale Konstituenten; (9) Regularität vs. Defektivität des Paradigmas; (10) Semantische Kompatibilität vs. Inkompatibilität der Konstituenten; (11) Semantische Ambiguität: eine Lesart vs. zwei Lesarten; (12) Motiviertheit vs. Opakheit.

Außer den beschriebenen Kriterien der Polylexikalität, Stabilität und Idiomatizität werden in den Definitionen der Phraseologismen ebenfalls andere Aspekte herangeführt: Viele Phraseologismen sind durch Bildhaftigkeit, Motiviertheit, Expressivität, Vagheit sowie das Auftreten der unikalen Komponenten gekennzeichnet. Nichts desto trotz spielen die ersten drei genannten Merkmale eine entscheidende Rolle bei der Einteilung der Phraseologie in die Phraseologie im engeren und die Phraseologie im weiteren Sinne. Für die Phraseologismen im weiteren Sinne werden die Polylexikalität und Stabilität aufweisenden Wortverbindungen betrachtet, zur Phraseologie im weiteren Sinne gehören infolgedessen z. B. Kollokationen (blondes Haar), Funktionsverbgefüge (eine Entscheidung treffen), Routineformeln (Guten Tag!), Sprichwörter (Was du heute kannst besorgen, das verschiebe nicht auf morgen), geflügelte Worte (Sein oder nicht sein). Im engeren Sinne umfasst der Terminus Idiome, also feste Wortverbindungen, die zusätzlich durch Idiomatizität gekennzeichnet sind.

Der so definierte Terminus des Phraseologismus im engeren Sinne weist viele Gemeinsamkeiten mit der Definition von Lewicki/Pajdzińska (2001: 315) auf. Sozial konventionalisierte Wortverbindungen implizieren den Mehrwortcharakter und die Festigkeit einer Spracheinheit, während das Auftreten von unikalen Komponenten (z. B. dt. Maulaffen freihalten; poln. ktoś leci w dyrdy, ktoś idzie na udry, wystrychnąć kogoś na dudka) oder Defektivität des Paradigmas (nur Vergangenheitsformen in der phraseologischen Lesart möglich: z. B. dt. Er hat ihr den Kopf gewaschen, *Er wäscht ihr den Kopf; poln. Z byka spadteś? *Z byka spadasz?) als ein Idiomatizitätsparameter angesehen werden. 
Die weite Auffassung der Phraseologie in der germanistischen Tradition entspricht dagegen der Definition von Bogusławski (1989), in der zwei obligatorische Merkmale des Phraseologismus vorausgesetzt werden: sein Mehrwortcharakter (Polylexikalität) und elementare Kompositionalität ( $\approx$ Festigkeit, Stabilität, Lexikalisierung, Reproduzierbarkeit), d. h. sein Status einer Spracheinheit und nicht des Produktes der Sprache.

\section{$3 \quad$ Klassifikationen der Phraseologismen}

In der polnischen Fachliteratur funktionieren einige nach verschiedenen Kriterien durchgeführte Klassifikationsvorschläge. Zu den wichtigsten Einteilungsaspekten gehören dabei semantische, grammatische und funktionale Kriterien, deren sich die meistzitierten Autoren Lewicki und Skorupka - bedienen.

Die ersten, heutzutage als klassisch betrachteten Systematisierungen der festgeprägten Wortverbindungen wurden von Skorupka (1969) vorgenommen, der Phraseologismen nach dem formalen und nach dem semantischen Kriterium eingliedert. Die formale (grammatische, synchronische) Klassifikation geht von dem grammatischen Charakter der Komponenten und der Art ihrer Verbindung aus. Aus dieser Perspektive differenziert Skorupka zwischen drei Klassen der Wortverbindungen: Die Ausdrücke (wyrażenia) umfassen Wortverbindungen, die aus wenigstens zwei Lexemen bestehen und einen nominalen Charakter aufweisen. Das Zentrum eines Ausdrucks macht dabei ein Nomen, ein Adjektiv, ein Partizip oder ein Adverb aus (vgl. pięta Achillesa 'die Achillesferse', pierwszy lepszy 'der erstbeste', wielce szanowny 'sehr geehrte', zbyt wcześnie 'zu früh'). Zu den Ausdrücken zählt der Begründer der polnischen Phraseologie ebenfalls festgeprägte präpositionalen und adverbialen Wortverbindungen wie (na chwile 'auf einen Augenblick', do jutra 'bis morgen'). Die Wendungen (zwroty) definierte Skorpuka als Gruppen syntaktisch zusammenhängender Lexemen, deren Hauptglied einen verbalen Charakter aufweist. Das Zentrum einer Wendung macht deswegen ein Verb oder unflektiertes Partizip aus (wołać wniebogłosy 'aus vollem Hals schreien', ruszyć $z$ kopyta $\approx$ 'mit Volldampf losgehen', ściśle mówiąc 'genauer gesagt'). Phrasen (frazy) bestehen dagegen aus verbalen und nominalen Komponenten, haben eine Satzform und sind zu einem gewissen Grade festgeprägt (z. B. Słońce wschodzi 'Die Sonne geht auf', Klamka zapadła $\approx$ 'Die Entscheidung ist gefallen').

In zahlreichen der formalen Klassifizierung der Phraseologismen gewidmeten Artikeln differenzierte Skorupka innerhalb der genannten Klassen weitere Subklassen. Die Phrasen lassen sich weiter in Maximen (maksymy), Sentenzen (sentencje), Sprichwörter, Sinnsprüche (porzekadła), Floskeln/Gemeinplätze (powiedzenia) eingliedern. Als spezielle Subklassen der Ausdrücke sind die sog. Reihenausdrücke ${ }^{10}$ (wyrażenia szeregowe) z. B. tu i tam 'hier und da', blaski $i$ cienie 'Licht- und Schattenseiten', wzloty i upadki 'Höhen und Tiefen', komparative Ausdrücke (wyrażenia porównawcze) z. B. blady jak kreda 'kreideweiß', czarny jak kruk 'rabenschwarz', prosty jak świeca 'kerzengerade' und gereimte Ausdrücke (wyrażenia rymowa-

\footnotetext{
10 Reihenausdrücke, Reihenwendungen weisen viele Gemeinsamkeiten mit den Zwillings- oder Paarformeln auf, die man als zwei Wörter der gleichen Wortart, die durch eine Konjunktion (bevorzugt und) zu einer paarigen Formel gebunden werden, definieren kann. Da die Zwillingsformeln aber sowohl Nomen (Schulter an Schulter), Adverbien (klipp und klar) als auch Verben (ackern und rackern, hegen und pflegen) verbinden können, haben wir uns im Folgenden für eine wörtliche Übersetzung entschieden.
} 
ne), z. B. nudy na pudy $\approx$ 'unerträgliche Langeweile', chtopek roztropek $\approx$ 'pfiffiges Kerlchen' $\mathrm{zu}$ nennen, während innerhalb der Wendungen die sog. komparativen Wendungen (zwroty porównawcze) z. B. strzec jak oka w głowie 'etw. wie seinen Augapfel hüten' sich ausdifferenzieren lassen. An diesen Vorschlag Skorupkas schließt sich 1974 Bąba an, indem er die Wendungen um weitere Subklassen: Reihenwendungen (połaczenia szeregowe) z. B. chuchać $i$ dmuchać 'hegen und pflegen' und gereimte Wendungen (połaczenia rymowane) z. B. było nie było $w$ to głupie ryło; chlup $w$ ten głupi dziób; chluśniem bo uśniem ${ }^{11}$ ausweitet. Im Endeffekt nimmt die synchronische Typologie Skorupkas (1969) mit den Ergänzungen von Bąba (1974) folgende Gestalt an:

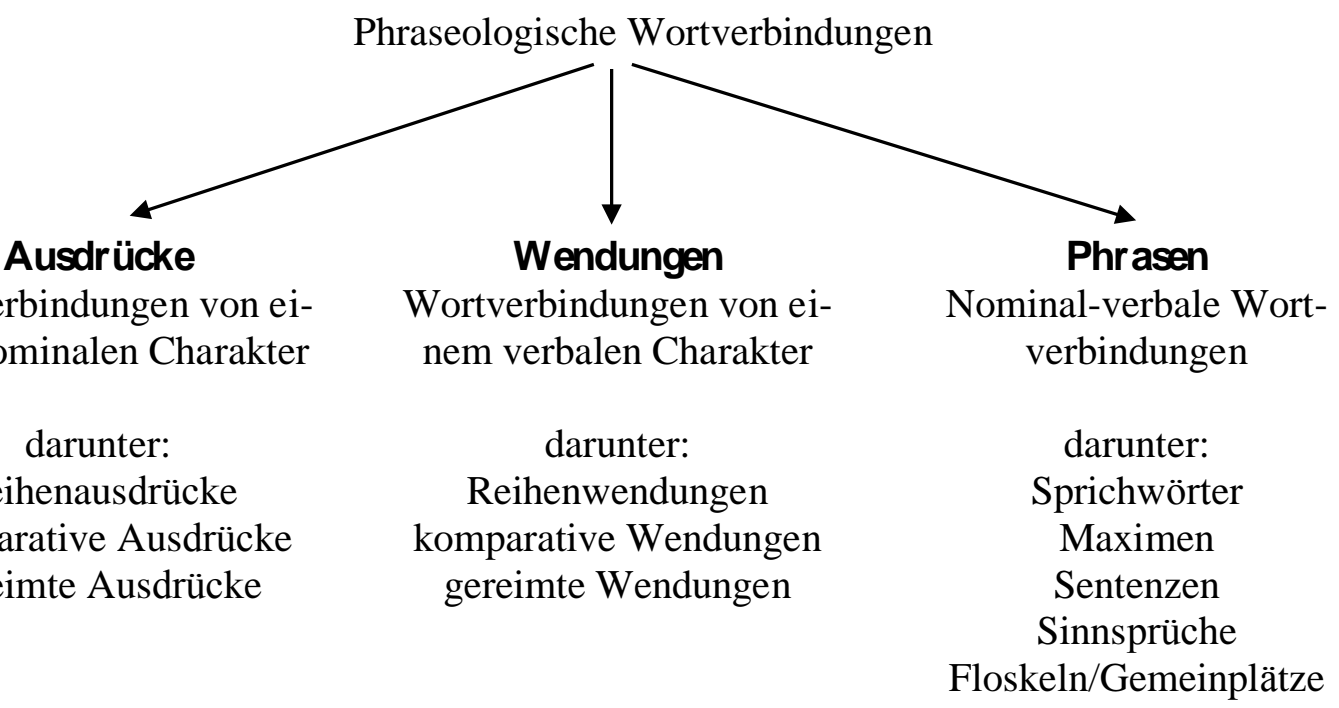

Abb. 1: Formale Klassifikation nach Skorupka (1969) mit Ergänzungen von Bąba (1974)

Den Ausgangspunkt der zweiten, semantischen Klassifikation von Skorupka macht der Lexikalisierungsgrad einer Wortverbindung, ihre formale und semantische Festigkeit. Skorupka bezeichnet diese Klassifikation als genetisch, mit ihrer Hilfe versucht er zu veranschaulichen, dass theoretisch jede Wortverbindung unter bestimmten Bedingungen phraseologisiert werden kann und umgekehrt: Jeder Phraseologismus kann in gewissen kommunikativen Kontexten zu einer freien Wortverbindung werden. Dazu schreibt er:

Die Geschichte der Phraseolgie ist als anhaltende, wenngleich langsame Bewegung zu verstehen, der Übergang von freien zu festen Wortverbindungen und umgekehrt. Diese formalen und semantischen Schwingungen zeugen davon, dass die Sprache kein erstarrtes Zeichensystem, sondern ein stetes Geschehen, eine Bewegung ist. ${ }^{12}$

(Skorupka 1952b: 180)

Aus der semantischen Perspektive differenziert Skorupka unter drei Klassen der Wortverbindungen: die festen, die kombinierbaren und die losen Wortverbindungen. Die festen Wortverbindungen (stałe zwiazki wyrazowe) betrachtet er dabei als lexikalische Einheiten, die in einer Äußerung wie ein Wort funktionieren. Ihre Bedeutung ergibt sich nicht aus der Summe ihrer Komponenten, weswegen sie ihre syntaktische Funktion wie ein Wort realisieren (z. B.

\footnotetext{
11 Die genannten Beispiele beziehen sich auf gereimte Trinksprüche.

12 "Dzieje frazeologii to ustawiczny, choć powolny ruch, to przechodzenie od zespoleń luźnych do stałych i odwrotnie. Te oscylacje formalne i znaczeniowe wyrażeń i zwrotów świadczą o tym, że język nie jest skostniałym systemem znaków, lecz ustawicznym stawaniem się, ruchem" (Skorupka 1952b: 180).
} 
zejść na psy 'vor die Hunde gehen', mieć się na baczności 'auf der Hut sein'). Die kombinierbaren Wortverbindungen (łaczliwe zwiazki wyrazowe) bilden nach Skorupka einen Übergangsbereich zwischen den festen und losen Wortverbindugnen. Sie sind durch einen beachtenswerten Grad der formalen Festigkeit und semantischen Kohäsion gekennzeichnet, ihre Komponenten sind dennoch nicht ganz lexikalisiert. Dementsprechend kann eine Komponente der Wortverbindung ihre wörtliche Bedeutung bewahren, während die ganze Wortverbindung dank dem metaphorischen Gebrauch der zweiten Komponente eine metaphorische Bedeutung aufweist (por. czarna rozpacz 'tiefe [wörtl. schwarze] Verzweiflung'). Die kombinierbaren Wortverbindungen lassen manchmal die Substituierbarkeit einer Komponente durch Synonyme zu (z. B. torować sobie drogę, ścieżkę, przejście 'sich den Weg, den Durchgang, den Pfad bahnen'). An den Rändern der festen und der kombinierbaren Phraseologie siedelt Skorupka die besonders oft in der Fachsprache auftretenden Gattungsbezeichnungen (ryba stodkowodna 'Süßwasserfisch', izba porodowa 'Entbindungsstation'), komparative Ausdrücke und Wendungen (blady jak kreda 'kreidenweiß', zachowywać się jak słoń w składzie porcelany 'sich benehmen wie ein Elefant im Porzellanladen') an. Unter den losen Wortverbindungen (zwiazki luźne) versteht Skorupka die ad hoc gebildeten Konstruktionen, deren Bedeutung sich aus der Summe der Komponenten ergibt (zielona sukienka 'ein grünes Kleid', drewniany stól 'ein hölzerner Tisch').

Beide Klassifikationsvorschläge Skorupkas sind mit der Zeit auf Kritik gestoßen. Der formalen Klassifikation warf man vor, dass sie den Verlust der syntaktischen Eigenschaften einer Wortart und die sich daraus ergebende Notwendigkeit der Klassifizierung der Phraseologismen nach der aktuellen Funktion der ganzen Wortverbindung nicht berücksichtigt (vgl. Lewicki 1976: 20). Die semantische Klassifikation wurde für die Verschwommenheit der Grenzen zwischen der Phraseologie und Syntax kritisiert, auch wenn Skorupka (1953: 3) auf ihren diachronischen Charakter verwies und betonte, dass er Phraseologismen für "mehr oder weniger formal und semantisch lexikalisierte Wortverbindungen" hält.

Zwei neue Klassifikationsvorschläge unter Einbezug des semantischen und des syntaktischen Kriteriums wurden von Lewicki unterbreitet. Aufgrund des semantischen Kriteriums teilt Lewicki die Phraseologismen in: Idiome (idiomy) und stereotype Wortverbindungen (frazesy, darunter hyperonymische Wortverbindungen). In Idiomen ist die "festgeprägte Bedeutung ganz anders als die, die aus den Bedeutungen der Komponenten folgt"13 (Lewicki/ Pajdzińska 2001: 318), z. B. chować głowe w piasek 'den Kopf in den Sand stecken', iść z kimś na udry $\approx$ 'gegen jmdn. Front machen', zbić kogoś z pantałyku $\approx$ 'jmdn. aus dem Konzept bringen'). In dieser Gruppe können also unikale Komponenten (udry, pantałyk) auftreten. Stereotype Wortverbinungen umfassen demgegenüber "festgeprägte Wortverbindungen, deren Sinn im Bedeutungsumfang des semantisch dominierenden Wortes liegt, auch wenn die ganze Wortverbindung semantisch irregulär ist"14 (Lewicki/Pajdzińska 2001: 319). Zu dieser Gruppe gehören folglich Wortverbindungen wie złodziej kieszonkowy 'Taschendieb', die sich auf Prozesse, Verläufe, Zustände beziehenden Wortverbindungen wie beispielshalber wpaść $w$

\footnotetext{
13 "ich utrwalone znaczenie jest zupełnie inne niż to, które wynika ze znaczeń członów składowych" (Lewicki/Pajdzińska 2001: 318).

14 "utrwalone połączenia wyrazów, których sens mieści się w zakresie znaczeniowym wyrazu dominującego semantycznie, jakkolwiek całe połączenie jest nieregularne znaczeniowo" (Lewicki/Pajdzińska 2001: 319).
} 
gniew 'in Zorn/Rage geraten', ktoś dokonuje wtamania, 'jmd. verübt einen Einbruch', sowie die phraseologischen Vergleiche, z. B. silny jak byk 'bullenstark'. Bei der Einteilung der Phraseologismen in Idiome und stereotype Wortverbindungen zieht Lewicki auch eindeutige Grenzen zwischen der Phraseologie und der Syntax: Die Domäne der ersten machen mehr oder weniger irreguläre Wortverbindungen aus, die zweite umfasst semantisch regulären Wortverbindungen.

Wesentlich komplexer ist die syntaktische Klassifikation, in der Lewicki fünf Klassen der Wortverbindungen: Phrasen (frazy), Wendungen (zwroty), nominale Ausdrücke (wyrażenia rzeczownikowe), bezeichnende Ausdrücke (wyrażenia określajace) und phraseologische Indikatoren (wskaźniki frazeologiczne) ausdifferenziert (vgl. Lewicki 1983). Manche der genannten Klassen lassen sich weiter subklassifizieren. Als erstes werden die Phraseologismen nach dem Kriterium der grammatischen Vollständigkeit der phraseologischen Konstruktion, ihrer Fähigkeit zur Konstituierung einer selbstständigen Äußerung eingeteilt. Aus dieser Perspektive lassen sich grammatisch vollständige und fragmentarische Einheiten unterscheiden. Grammatisch vollständig sind Phrasen, die keine Ergänzungen erfordern und selbständig als Äußerungen fungieren können (Kto rano wstaje, temu Pan Bóg daje $\approx$ 'Morgenstunde hat Gold im Munde', Bomba wybuchta 'Die Bombe ist geplatzt'). Innerhalb dieser Gruppe differenziert man zwischen den selbständigen und lexikalisch angeschlossenen Phrasen. Lexikalisch angeschlossene Phrasen sind zwar grammatisch komplett, gehen aber "eine obligatorische koordinierte Verbindung mit den vorangegangenen Sätzen ein"15 (Lewicki 1983: 80), was die Konstruktionen ... i po krzyku, 'und damit ist die Sache erledigt', ... i basta 'und damit basta' veranschaulichen.

Fragmentarische Einheiten unterzieht man weiteren Einteilungen "je nachdem, mit welchen Kontextbestandteilen sie zur Bildung einer grammatisch unabhängigen Konstruktion - eines Satzes oder eines Satzäquivalentes - fähig sind"16 (Lewicki 1983: 79).

Wendungen werden mit einem nominalen Satzglied oder mit nominalen Satzgliedern ergänzt, die auf der Oberfläche die Argumente der prädikativ-argumentativen Struktur ausmachen. Die Einführung von entsprechenden Ausdrücken und temporal-modale Aktualisierung wandeln die Wendung in einen Satz um. Die Wendungen teilt man des Weiteren in die Wendungen des Nexus (zwroty związu głównego) und die Wendungen der verbalen Gruppe ein. In den Wendungen des Nexus ist die Subjektstelle besetzt, sie erfordern aber Ergänzungen in Form vom obliquen Kasus, Sätzen, Adjektiven, Possesivpronomen (żoładek podchodzi komuś do gardta 'der Magen dreht sich jmdm. um', żal zalewa komuś serce 'Trauer erfüllt jmds. Herz'). Bei den Wendungen der verbalen Gruppe ist die Subjektposition und ev. die Position des obliquen Kasus leer (ktoś zbija bąki $\approx$ 'jmd. dreht Däumchen').

Die nominalen und bezeichnenden Ausdrücke bilden einen Satz erst in der Verknüpfung mit einem Verb in der Prädikatsfunktion. Die nominalen Ausdrücke können dabei eine Subjektfunktion einnehmen, sie ersetzen in den Sätzen Substantive (waskie gardło 'Engpass', oko cyklonu 'Auge des Zyklons'). Die bezeichnenden Ausdrücke dienen - wie der Name zeigt -

\footnotetext{
15 "obligatoryjny związek współrzędny ze zdaniami poprzedzającymi" (Lewicki 1983: 80).

16 "według tego, z jakimi składnikami kontekstu są one zdolne utworzyć konstrukcję gramatycznie niezależną, czyli zdanie lub jego równoważnik" (Lewicki 1983: 79).
} 
der Bezeichnung von Substantiven, Adjektiven, Verben und Adverbien. Manche treten ausschließlich in der adnominalen ( $w$ czepku urodzony 'unter einem glücklichen Stern geboren', kuty na cztery nogi $\approx$ 'mit allen Wassern gewaschen'), andere in der adverbalen oder adadjektivischen (krótko $i$ węzłowato 'kurz und bündig', tu i tam 'hier und da') Position auf. Die meisten bezeichnenden Ausdrücke unterliegen dennoch keinen derartigen Einschränkungen ( $n a$ amen: obrazit się, obraza, ,wörtl. auf Amen $\approx$ 'endgültig: sich beleidigt fühlen, Beleidigung').

Am wenigsten ist die letzte Klasse der fragmentarischen Phraseologismen - die phraseologischen Indikatoren untersucht. Sie haben eine Hilfsfunktion inne und fungieren als Präpositionen: (w ramach czegoś 'im Rahmen von', w oparciu o coś 'in Anlehnung an'), Konjunktionen (zarówno ... jak $i$... 'sowohl ... als auch', baqdź ..., baqdź... 'weder ... noch'), Partikeln (też coś! 'na so was').

Die funktional-syntaktische Klassifikation Lewickis veranschaulicht folgendes Schema:

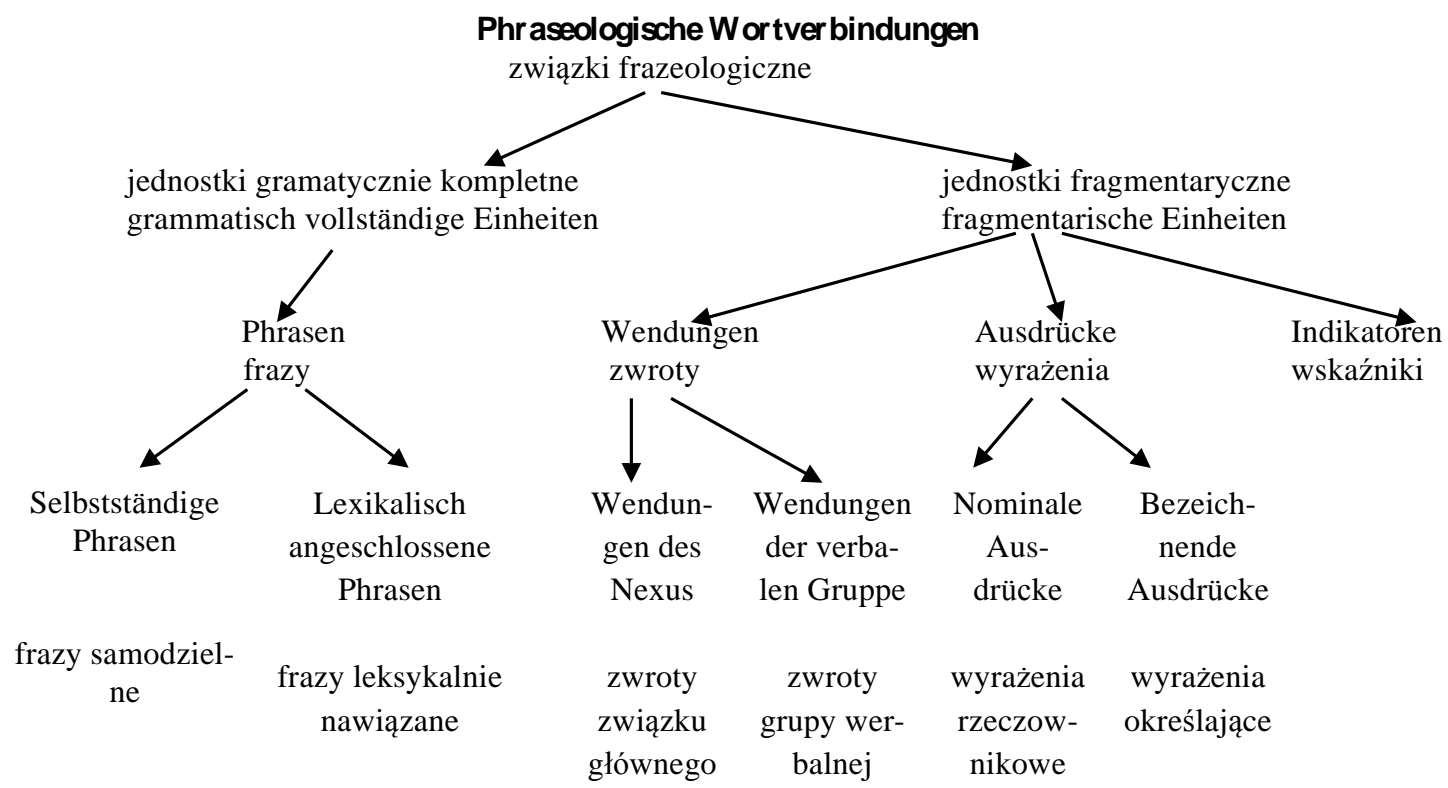

Abb. 2: Funktional-syntaktische Klassifikation von A. M. Lewicki (1983)

Lewickis Typologien der Phraseologismen sind heutzutage am häufigsten verwendet, einen nicht zu unterschätzenden Beitrag zu ihrer Popularität hat ihre Aufnahme in einen von Jerzy Bartmiński (2001) herausgegebenen enzyklopädischen Leitfaden durch das gegenwärtige Polnisch geleistet.

Der Genauigkeit halber ist noch die in dem letzten Jahrzehnt erschienene Klassifikation der Phraseologismen von P. Müldner-Nieckowski zu erwähnen. Der Autor des Phraseologischen Großwörterbuches der Polnischen Sprache stellt sie in dem Vorwort zu seinem Werk dar, wo er zwischen den offenen, geschlossenen und formalen Phraseologismen differenziert. Zu den offenen Phraseologismen (frazeologizmy otwarte) gehören dabei die "semantisch autonomen Wortverbindungen, die ihre endgültige Form auf der Grundlage der Muster erhalten"17 (2003: 16) wie z. B. czyjeś akcje idą w górę 'jmds. Aktien steigen'. Die geschlossenen Phraseologismen (frazeologizmy zamknięte) bilden "semantisch autonome Wortverbindungen, die keine

\footnotetext{
17 "autonomiczne znaczeniowo zespoły wyrazów, które przyjmują ostateczną postać na podstawie wzorców" (Müldner-Nieckowski 2003: 16).
} 
Leerstellen aufweisen"18 (2003: 18), z. B. uśmiech losu $\approx$ 'eine glückliche Fügung'. Die formalen Phraseologismen (frazeologizmy formalne) werden als "kurze polylexikalen Äußerungen, die nur eine Bedeutung und nur eine unantastbare Form haben"19 (2003: 18) wie na prawo patrz 'Augen rechts!' definiert. Eine leicht modifizierte Version dieser Klassifikation finden wir ebenfalls in Müldner-Nieckowskis Monographie Frazeologia poszerzona ('Erweiterte Phraseologie') (2007).

Syntaktische und semantische Kriterien sind ebenfalls in der germanistischen Phraseologie zur Klassifikation der heterogenen Klasse der Wortverbindungen herangezogen worden. Ebenfalls hier werden die Klassifizierungen anhand der semantischen (vgl. z. B. Agricola 1977; Korhonen 2002), der morpho-syntaktischen (vgl. Fix 1974; Fleischer 1982) oder semantischen und syntaktischen (vgl. z. B. Černyševa 1975; Rothkegel 1973) Kriterien vorgenommen. Die pragmatische Klassifikation von Coulmas (1981) bezieht sich auf den kommunikativen Wert der Phraseologismen und hat einen funktionalen Charakter.

Die neuesten Systematisierungsversuche sind dennoch durch die Kombination von verschiedenen Kriterien gekennzeichnet. Dementsprechend bedient sich Burger (2010: 36-44) in seiner Basisklassifikation, die an dieser Stelle in groben Umrissen dargestellt wird, aller drei Kriterien.

Als erstes werden die Phraseologismen im weiteren Sinne nach dem Kriterium der Zeichenfunktion in: (i) referentielle Phraseologismen, die sich auf Objekte, Vorgänge oder Sachverhalte der Wirklichkeit beziehen (z. B. Schwarzes Brett; jmdn. übers Ohr hauen), (ii) die grammatische Relationen herzustellenden strukturellen Phraseologismen (z. B. sowohl ... als auch) und (iii) kommunikative Phraseologismen, die für die Herstellung, Definition, den Vollzug und die Beendigung kommunikativer Handlungen von Relevanz sind (z. B. Guten Morgen; meiner Meinung nach) eingeteilt (vgl. Burger 2010: 36).

Die größte Gruppe der referentiellen Phraseologismen lässt sich dabei in nominative und propositionale Phraseologismen anhand von zwei Kriterien eingliedern. Die nominativen Phraseologismen bezeichnen in semantischer Hinsicht Objekte und Vorgänge, in syntaktischer Hinsicht sind sie satzgliedwertig, d. h. sie umfassen die Spracheinheiten unterhalb der Satzgrenze (z. B. Schwarzes Brett). Die propositionalen Phraseologismen dagegen fungieren als Aussagen über Objekte und Vorgänge und sind aus syntaktischer Perspektive satzwertig (z. B. Ihr habt zu Hause wohl die Säcke an den Türen?; Morgenstunde hat Gold im Munde).

Für die weitere Untergliederung der nominativen Phraseologismen zieht Burger das semantische Kriterium heran. Nach dem Grad der Idiomatizität lassen sich die satzgliedwertigen Phraseologismen in Idiome (z. B. ins Gras beißen), Teil-Idiome, in denen nicht alle Komponenten umgedeutet sind (z. B. einen Streit vom Zaune brechen) und nicht-idiomatische bzw. schwach-idiomatische Kollokationen (z. B. blondes Haar; Zähne putzen) subklassifizieren.

\footnotetext{
18 "autonomiczne znaczeniowo zespoły wyrazów, które nie mają elementów otwartych" (Müldner-Nieckowski 2003: 18).

19 "krótkie, wielowyrazowe wypowiedzenia, które mają i muszą mieć tylko jedno znaczenie i tylko jedną, nienaruszalną postać" (ebd.).
} 
Da die Anwendung des Idiomatizitätsgrades als primäres Eingliederungskriteriums der propositionalen Phraseologismen die traditionell gut etablierte Klasse der Sprichwörter auseinanderreißen würde (vgl. das idiomatische Sprichwort: Der Apfel fällt nicht weit vom Stamm vs. das nicht-idiomatische Sprichwort: Durch Schaden wird man klug), entscheidet sich Burger (ebd. 38-42) bei der Einteilung dieser Gruppe für eine syntaktische/textlinguistische Klassifikation und unterscheidet unter zwei großen Gruppen der Phraseologismen: Feste Phrasen sind explizit an den Kontext durch bereits verfestigte Komponenten (vgl. das deiktische Demonstrativpronomen Das schlägt dem Fass den Boden aus) oder ad hoc formulierte Elemente (z. B. jmds. Aktien steigen) angeschlossen. Topische Formeln umfassen satzwertige Phraseologismen, die durch kein lexikalisches Element mit dem Kontext verbunden sein müssen, vgl. die Sprichwörter (z. B. Ohne Fleiß kein Preis) oder Gemeinplätze (z. B. Was sein muss, muss sein; Man lebt nur einmal).
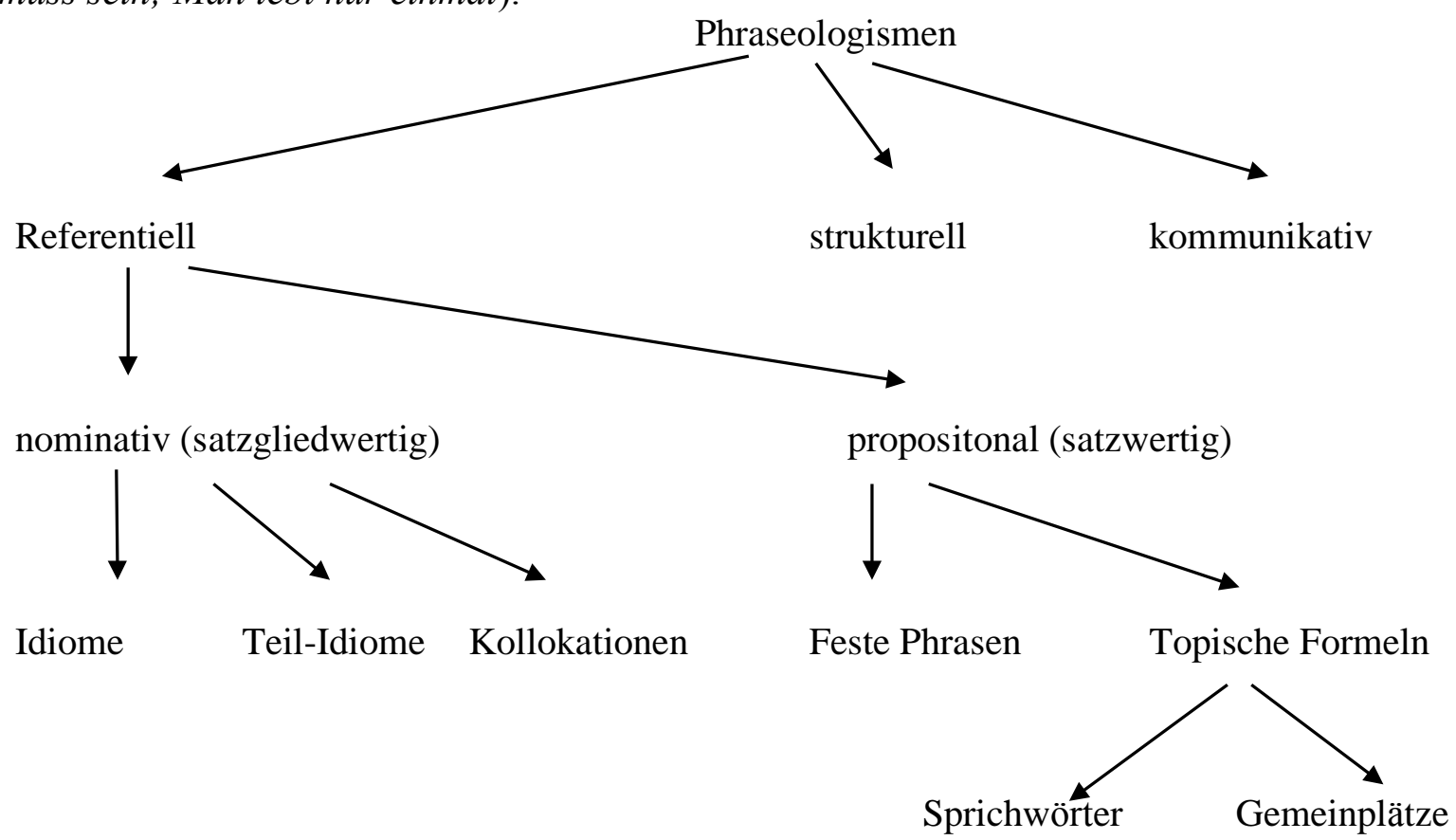

Abb. 3: Klassifikation der Phraseologismen von Burger (2010)

Beim Vergleich der in der Fachliteratur am meisten zitierten Klassifizierungen von Burger und Lewicki fallen - trotz deutlicher terminologischer Differenzen und unterschiedlicher Bedeutungen, die den Termini: Wendung, Ausdruck zugeschrieben werden - die entlang den parallelen Achsen verlaufenden Einteilungen auf. Die wichtigsten Einteilungskriterien bilden dementsprechend das semantische Kriterium, das die stabilen Mehrwortverbindungen in mehr oder weniger irreguläre subklassifiziert sowie das syntaktische Kriterium, bei dem die entscheidende Untergliederungslinie sich auf den syntaktischen Vollständigkeitsgrad (satzgliedwertige vs. satzwertige Phraseologismen) bezieht.

Mit Nachdruck muss dennoch unterstrichen werden, dass die vorgeschlagenen Klassifizierungen einen Orientierungswert haben und der Ganzheit der zur Phraseologie zählenden Sprachphänomene nicht gerecht werden. In beiden Sprachen existieren beispielshalber Phraseologismengruppen, die von den Basisklassifikationen nicht erfasst werden bzw. quer zu ihnen liegen: Zahlreiche Beispiele für das Deutsche (Modellbildungen, Zwillingsformeln, Ki- 
negramme u. a.) führt Burger (2010: 44-51), für das Polnische Chlebda ${ }^{20}$ (2005: 82-83) heran. Die Klassifikationen bedienen sich von Natur aus der Dichotomie, bauen auf dem entweder-oder-Prinzip, setzen die Möglichkeit eindeutiger Grenzziehungen voraus, wodurch sie das Wesen der Phraseologie vereinfachen. Dazu schreibt Chlebda:

... Dichomatisierung des Weltbildes, auch wenn sie in der Anfangsphase der Realitätserkennung unerlässlich ist, befindet sich doch in dem "steten Nicht-Anpassungskonflikt" (A. Schaff) mit seiner faktischen Natur. Die Realität ist dynamisch, unbeständig, sie beruht, einem klassischen Ausdruck nach, auf "Einheit und Kampf der Gegensätze", wodurch ihre Bestandteile einen relativen, dialektisch widersprüchlichen Charakter $(\mathrm{p} / \mathrm{q})(\mathrm{q} / \mathrm{p})$ haben. ${ }^{21}$

(Chlebda 2003: 35)

\section{Schlussfolgerungen}

Auch wenn wir uns dessen bewusst sind, dass diese Darstellung nur einen skizzenhaften Charakter hat und auch die annähernde Vollständigkeit der Problematik nicht erreichen kann, versuchen wir schlussfolgernd auf einige Gemeinsamkeiten zwischen der deutschen und polnischen Phraseologie zu verweisen.

In der Entwicklung der deutschen und der polnischen Phraseologie sind zahlreiche Analogien sichtbar: In beiden Ländern zeichnet sich deutlich die vorwissenschaftliche Phase aus, in der man feste Wortverbindungen zu lexikographischen Zielen gesammelt hat. Zum Gegenstand der wissenschaftlichen Reflexion wurden die Phraseologismen sowohl in Deutschland als auch in Polen erst in der 2. Hälfte des 20. Jhs. In den Arbeiten von Skorpuka und Černyševa sind dabei die gemeinsamen Wurzeln, die auf die Pioniere der europäischen phraseologischen Tradition: Charles Bally und Viktor V. Vinogradov sowie die darauf aufbauende sowjetische Phraseologie zurückzuführen sind, deutlich sichtbar.

Zur Definierung der grundlegenden Termini sind die deutsche und die polnische Phraseologie auf verschiedenen Wegen gekommen: Während die Ausarbeitung der Definition und der Phrasologizitätskriterien ein explizites Ziel der phraseologischen Anfangsphase in Deutschland bildete, baute die polnische Phraseologie in den terminologischen Angelegenheiten lange auf den Autoritäten von Skorupka und Lewicki auf. Endgültig konstituierte sich dennoch in beiden Ländern die von dem Modell "Zentrum-Peripherie" ausgehende Betrachtungsweise: Phraseologismen sind heutzutage als eine radiale Kategorie beschrieben, statt einer eindeutigen Definition werden sie durch den Ähnlichkeitsgrad mit typischen Vertretern der Klasse charakterisiert, wobei man ein breites Spektrum der Grenzerscheinungen akzeptiert. Treffend fasst dies Fleischer (1982: 34) zusammen: "Ein Kernbereich lässt sich relativ gut erfassen; für die Grenzbereiche sind unterschiedliche Auffassungen zu akzeptieren."

In den letzten Jahren wird in der deutschen und polnischen Phraseologie die Tendenz deutlich spürbar, die Grenzen der Phraseologie und ihren Forschungsbereich wesentlich zu erweitern.

\footnotetext{
${ }^{20}$ Vgl. klassische Phraseologismen (frazeologizmy klasyczne) z. B. pięta Achillesa 'Achillesferse'), metasprachliche und metatextuelle Operatoren (operatory metajęzykowe i metatekstowe) z. B. jak to się mówi 'wie man sagt', ciag dalszy nastapi 'die Fortsetzung folgt' u. a. (vgl. Chlebda 2005: 82-83).

21 ...dychotomizowanie obrazu świata, jakkolwiek nieodzowne we wstępnym poznawaniu rzeczywistości, znajduję się w stałym "konflikcie niedopasowania" (A. Schaff) z jego faktyczną naturą. Rzeczywistość jest dynamiczna, zmienna, stanowi ją, wedle klasycznego wyrażenia "jedność i walka przeciwieństw", przez co jej elementy mają charakter względny, dialektycznie sprzeczny: (p/q) (q/p) (vgl. Chlebda 2003: 35).
} 
Unter dem Einfluss der Korpuslinguistik und der kognitiven Linguistik werden die Thesen über die volle Kompositionalität vieler freien Wortverbindungen sowie über klare Grenzen zwischen Lexikon und Grammatik in Zweifel gezogen (Langacker 1987, 2008; Fillmore/Kay/O'Connor 1988; Taylor 2003). Immer häufiger wird die Ansicht vertreten, dass die Sprache in wesentlich größerem Ausmaß aus mehr oder weniger fixierter Mehrwortverbindungen zusammengebaut ist (Hausmann 1997; Stubbs 2001; Taylor 2003). Fillmore u. a. fassen die Idiomatizität beispielshalber so auf:

We think of a locution or manner of speaking as idiomatic, if it is assigned an interpretation by the speech community but if somebody who merely knew the grammar and the vocabulary of a language could not, by virtue of the knowledge alone, know (i) how to say it, or (ii) what it means, or (iii) whether it is a conventional thing to say. Put differently, an idiomatic expression or construction is something, a language user could fail to know while knowing everything else in the language.

(Fillmore/Kay/O'Connor 1988: 504)

Diese Auffassung verschiebt die Phraseologie ins Zentrum der Sprachwissenschaft, macht ihre Grenzen zugleich sehr verschwommen und intersubjektiv schwer definierbar.

\section{Literatur}

Bańko, Mirosław (2001): Z pogranicza leksykografii i językoznawstwa. Warszawa: Wydział Polonistyki Uniwersytetu Warszawskiego.

Bąba, Stanisław (1974): "W sprawie klasyfikacji polskich jednostek frazeologicznych (zwrot szeregowy, zwrot rymowany)". Prace Filologiczne XXV: 377-385.

Bąba, Stanisław (1979): Kultura języka polskiego. Zagadnienia poprawności językowej w zakresie frazeologii. Poznań: Wydawnictwo Naukowe UAM.

Bąba, Stanisław (1989): Innowacje frazeologiczne współczesnej polszczyzny. Poznań: Wydawnictwo Naukowe UAM.

Bąba, Stanisław (1998): Materiaty do bibliografii frazeologii polskiej. Prace opublikowane w latach 1945-1995. Poznań: WiS.

Bąba, Stanisław (2003): Materiały do bibliografii frazeologii polskiej. Prace opublikowane w latach 1996-2000. Poznań: Poznańskie Studia Polonistyczne.

Bąba, Stanisław (2008): Materiały do bibliografii frazeologii polskiej. Prace opublikowane w latach 2001-2005. Poznań: Wydawnictwo Poznańskie.

Bogusławski, Andrzej (1989): "Uwagi o pracy nad frazeologią". In: Saloni, Zygmunt (ed.): Studia z polskiej leksykografii współczesnej III. Białystok, Dział Wydawnictw Filii Uniwersytetu Warszawskiego: 13-30.

Borejszo, Maria (1985): "O archaizmach leksykalnych i semantycznych w stałych związkach wyrazowych współczesnej polszczyzny (na materiale "Słownika języka polskiego" pod redakcją Mieczysława Szymczaka)". Poradnik Językowy 6: 341-349.

Burger, Harald (1973): Idiomatik des Deutschen. Tübingen: Niemeyer. (= Germanistische Arbeitshefte 16).

Burger, Harald (2010): Phraseologie. Eine Einführung am Beispiel des Deutschen. Berlin: Schmidt.

Burger, Harald u. a. (ed.) (1982): Handbuch der Phraseologie. Berlin/New York: de Gruyter.

Burger, Harald u. a. (2007a): "Ein-führung/Subject area, terminology and research topics". In: Burger, Harald u. a. (ed.): Phraseologie/Phraseology. Ein internationales Handbuch zeitISSN 1615-3014 
genössischer Forschung/An International Handbook of Contemporary Research. 1. Halbband. Berlin, de Gruyter Mouton: 1-10. (= HSK 28,1/2).

Burger, Harald u. a. (ed.) (2007b): Phraseologie/Phraseology. Ein internationales Handbuch zeitgenössischer Forschung/An International Handbook of Contemporary Research. 1. Halbband. Berlin, de Gruyter Mouton: 619-644. (= HSK 28,1/2).

Černyševa, Irina (1970): Frazeologija sovremennogo nemeckogo jazyka. Moskau: Vysšaja škola.

Černyševa, Irina I. (1975): "Phraseologie". In: Stepanova, Maria D./Černyševa, Irina (ed.): Lexikologie der detuschen Gegenwartssprache. Moskau, Vysšaja škola: 198-261.

Chlebda, Wojciech (1991): Elementy frazematyki. Wprowadzenie do frazeologii nadawcy. Opole: Wydawnictwo WSP im. Powstańców Śląskich.

Chlebda, Wojciech (2001): "Frazeologia". In: Gajda, Stanisław (ed.): Najnowsze dzieje języków słowiańskich. Język polski. Opole, Uniwersytet Opolski: 178-206.

Chlebda, Wojciech (2003): Elementy frazematyki: Wprowadzenie do frazeologii nadawcy. Łaski: Oficyna Wydawnicza Leksem.

Chlebda, Wojciech (2005): Szkice o skrzydlatych słowach. Interpretacje lingwistyczne. Opole: Uniwersytet Opolski.

Coulmas, Florian (1981): Routine im Gespräch. Zur pragmatischen Fundierung der Idiomatik. Düsseldorf: Athenaion.

Dausendschön-Gay, Ulrich/Gülich, Elisabeth/Krafft, Ulrich (2007): "Phraseologische/ formelhafte Texte". In: Burger, Harald u. a. (ed.): Phraseologie. Ein internationales Handbuch zeitgenössischer Forschung. Berlin/New York, de Gruyter: 468-481.

Dobrovol'skij, Dmitrij (1995): Kognitive Aspekte der Idiom-Semantik. Studien zum Thesaurus der Idiom-Semantik. Tübingen: Narr.

Dobrovol'skij, Dmitrij (1997): Idiome im mentalen Lexikon: Ziele und Methoden der kognitivbasierten Phraseologieforschung. Trier: Wissenschaftlicher Verlag.

Donalies, Elke (1994): "Idiom, Phraseologismus oder Phrasem? Zum Oberbegriff eines Bereichs der Linguistik". Zeitschrift für germanistische Linguistik 22: 334-339.

Doroszewski, Witold (1954): Z zagadnień leksykografii polskiej. Warszawa: PIW.

Doroszewski, Witold (1958): "Wstęp". In: Doroszewski, Witold (ed.): Stownik języka polskiego. Warszawa, PWN: VII-XLVIII.

Dziamska-Lenart, Gabriela (2010): "110 lat polskiej frazeologii". In: Bąba, Stanisław/Skibski, Krzysztof/Szczyszek, Michał (ed.): Perspektywy wspótczesnej frazeologii polskiej. Teoria. Zagadnienia ogólne. Poznań, Wydawnictwo Naukowe Uniwersytetu im. Adama Mickiewicza w Poznaniu: 163-193.

Fillmore, Charles/Kay, Paul/O'Connor, Mary C. (1988): "Regularity and Idiomaticity in Grammatical Constructions: The Case of Let Alone". Language 64/3: 501-538.

Fix, Ulla (1971): Das Verhältnis von Syntax und Semantik im Wortgruppenlexem. Versuch einer objektivierten Klassifizierung und Definition des Wortgruppenlexems. Leipzig: KarlMarx-Universität.

Fleischer, Wolfgang (1982): Phraseologie der deutschen Gegenwartssprache. Leipzig: VEB Bibliographisches Institut.

Fleischer, Wolfgang (1997): Phraseologie der deutschen Gegenwartssprache. Tübingen: Niemeyer. 
Häusermann, Jürg (1977): Phraseologie. Hauptprobleme der deutschen Phraseologie auf der Basis sowjetischer Forschungsergebnisse. Tübingen: Niemeyer.

Hessky, Regina (1992): "Grundfragen der Phraseologie". In: Ágel, Vilmos/Hessky, Regina (ed.): Offene Fragen, offene Antworten in der Sprachgermanistik. Tübingen, Niemeyer: 77-94.

Hessky, Regina (2000): "Entwicklungen der Phraseologie seit Mitte des 20. Jahrhunderts". In: Bensch, Werner u. a. (ed.): Sprachgeschichte. Ein Handbuch zur Geschichte der deutschen Sprache und ihrer Erforschung. Berlin/New York, de Gruyter: 2101-2106.

Hümmer, Christiane (2009): Synonymie bei phraseologischen Einheiten. Eine korpusbasierte Untersuchung. Frankfurt a.M.: Lang.

Jaksche, Harald/Sialm, Ambros/Burger Harald (ed.) (1981): Reader zur sowjetischen Phraseologie. Berlin/New York: de Gruyter.

Kania, Stanisław/Tokarski, Jan (1984): Zarys leksykologii i leksykografii polskiej. Warszawa: Wydawnictwa Szkolne i Pedagogiczne.

Korhonen, Jarmo (2002): "Typologien von Phraseologismen. Ein Überblick". In: Cruse, Alan D. u. a. (ed.): Lexikologie/Lexicology. Ein internationales Handbuch zur Natur und Struktur von Wörtern und Wort-schätzen/An International Handbook on the Nature and Structure of Words and Vocabularies. 1. Halbband. Berlin/New York, de Gruyter ton: 402-408. (= HSK 21, 1/2).

Krasnowolski, Antoni (1905-1906): Przenośnie mowy potocznej. Warszawa: M. Arcta.

Krawczuk, Ałła (2011): Leksykologia i kultura języka polskiego. Kijów: INKOS.

Langacker, Ronald (1987): Foundations of Cognitive Grammar. Theoretical Prerequisites. Standford: Standford University Press.

Langacker, Ronald (2008): Cognitive Grammar. A Basic Introduction. Oxford: Oxford University Press.

Lewicki, Andrzej Maria (1973): "Warianty zwrotów frazeologicznych". Sprawozdania z Posiedzeń Komisji Naukowych Pan. Oddziat w Krakowie XVII/2: 386-388.

Lewicki, Andrzej Maria (1976): Wprowadzenie do frazeologii syntaktycznej, teoria zwrotu frazeologicznego. Katowice: Uniwersytet Śląski.

Lewicki, Andrzej Maria (1981): "Derywacja frazeologiczna - najwyższy współcześnie stopień abstrakcji w poznawaniu zasobu frazeologicznego języka". In: Bartmiński, Jerzy (ed.): Pojęcie derywacji w lingwistyce. Lublin, Wydawnictwo UMCS: 71-89.

Lewicki, Andrzej Maria (1982a): "O motywacji frazeologizmów". In: Basaj, Mieczysław/Rytel, Danuta (ed.): Z problemów frazeologii polskiej i stowiańskiej II, Wrocław usw., Ossolineum: 33-47.

Lewicki, Andrzej Maria (1982b): "Problemy metodologiczne wariantywności związków frazeologicznych". In: Lewicki, Andrzej Maria (ed.): Stałość i zmienność związów frazeologicznych. Lublin, Uniwersytet Marii Curie-Skłodowskiej: 427-435.

Lewicki, Andrzej Maria (1983): "Składnia związków frazeologicznych". Biuletyn Polskiego Towarzystwa Językoznawczego XL: 75-83.

Lewicki, Andrzej Maria (1985): "Motywacja globalna frazeologizmów. Znaczenia przenośne, symboliczne i stereotypowe". In: Basaj, Mieczysław/Rytel, Danuta (ed.): Z problemów frazeologii polskiej i słowiańskiej III. Wrocław usw., Ossolineum: 7-23.

Lewicki, Andrzej Maria (1986 a): "Historia pola frazeologicznego Upijać się/ upić się w języku polskim". Poradnik Językowy 1: 36-41. 
Lewicki, Andrzej Maria (1986 b): "Słownik a gramatyka w leksykograficznym opisie związków frazeologicznych". In: Basaj, Mieczysław (ed.): Typy opisów gramatycznych języka. Materiały polsko-czeskiej sesji naukowej. Jabłonna 15-17.09.1983. Wrocław: Ossolineum.

Lewicki, Andrzej, Maria (1990): "Rola motywacji w opisowym słowniku zwrotów idiomatycznych". In: Rybicka, Halina/Rocławski, Bronisław (ed.): Tradycja i nowoczesność w nauczaniu cudzoziemców języka polskiego. Materiaty z ogólnopolskiej konferencji na temat: Nauczanie języka polskiego i kształcenie polonistyczne cudzoziemców, Gdańsk 17-18 X 1988. Gdańsk, Wydawnictwo Uniwersytetu Gdańskiego: 64-73.

Lewicki, Andrzej, Maria (1992): "Zakres frazeologii". Acta Universitatis Lodziensis IV: 2534.

Lewicki, Andrzej Maria (1994): "O możliwości pojęcia formantu we frazeologii". In: Basaj, Mieczysław/Rytel, Danuta (ed.): Z problemów frazeologii polskiej i słowiańskiej. Band 6. Warszawa, Slawistyczny Ośrodek Wydawniczy: 21-25.

Lewicki, Andrzej Maria/Pajdzińska, Anna (2001): "Frazeologia". In: Bartmiński, Jerzy (ed.): Współczesny język polski. Lublin: Wydawnictwo UMCS.

Lewicki, Andrzej/Pajdzińska Anna/Rejakowa Bożena (1987): Z zagadnień frazeologii. Problemy leksykograficzne. Warszawa: PWN.

Markowski, Andrzej (2012): Wykłady z leksykologii. Warszawa: PWN.

Müldner-Nieckowski, Piotr (2007): Frazeologia poszerzona. Studium leksykograficzne. Warszawa: Oficyna Wydawnicza Volumen.

Müller, Peter O./Kunkel-Razum, Kathrin (2007): "Phraseographie des Deutschen". In: Burger, Harald u. a.. (ed.): Phraseologie - Phraseology. Ein internationales Handbuch zeitgenössischer Forschung. Berlin/New York, de Gruyter: 939-949.

Palm, Christine (1995): Phraseologie. Eine Einführung. Tübingen: Narr.

Rothkegel, Annely (1973): Feste Syntagmen. Grundlagen, Strukturbeschreibung und automatische Analyse. Tübingen: Niemeyer.

Sinko, Tadeusz (1939): Klasyczne przysłowia w polszczyźnie. Lwów/Warszawa: KsiążnicaAtlas.

Skorupka, Stanisław (1950a): "Poprawność stylistyczna grup frazeologicznych". Poradnik Językowy 6: 1-4.

Skorupka, Stanisław (1950b): "Z dziejów frazeologii polskiej". Biuletyn Polskiego Towarzystwa Językoznawczego: 165-166.

Skorupka, Stanisław (1951): "Dobór wyrazów a dobór frazeologiczny". Poradnik Językowy 1: $17-21$.

Skorupka, Stanisław (1952a): "Frazeologia a semantyka". Poradnik Językowy 7: 9-16, 8: 1725.

Skorupka, Stanisław (1952b): "Z zagadnień frazeologii". Sprawozdania Komisji Językowej Łódzkiego Towarzystwa Naukowego IV: 147-180.

Skorupka, Stanisław (1953): "Z zagadnień frazeologii". Poradnik Językowy 8: 3-10.

Skorupka, Stanisław (1958a): "Frazeologia a składnia". Biuletyn Polskiego Towarzystwa Językoznawczego XVII: 97-114.

Skorupka, Stanisław (1958b): Język polski. Wiadomości i ćwiczenia z zakresu słownictwa, frazeologii i stylistyki. Klasa X. Warszawa: Państwowe Zakłady Wydawnictw Szkolnych.

Skorupka, Stanisław (1960): "Frazeologia a stylistyka". Poradnik Językowy 3: 97-111. 
Skorupka, Stanisław (1965): "Z zagadnień frazeologii porównawczej". Prace Filologiczne XVIII: 119-132.

Skorupka, Stanisław (1968a): Język polski. Wiadomości i ćwiczenia z zakresu słownictwa, frazeologii i stylistyki. Podręcznik dla klasy II liceum ogólnokształcącego, techników $i$ liceów zawodowych. Warszawa: Państwowe Zakłady Wydawnictw Szkolnych.

Skorupka, Stanisław (1968b): "Poprawność frazeologiczna połączeń wyrazowych". Poradnik Językowy 8: 385-392.

Skorupka, Stanisław (1969): "Podstawy klasyfikacji jednostek frazeologicznych". Prace Filologiczne XIX: 219-226.

Skorupka, Stanisław (1972): "Idiomatyzmy frazeologiczne we współczesnym języku polskim". Poradnik Językowy 3: 121-132.

Skorupka, Stanisław (1973): "Struktura frazeologiczna w językach słowiańskich". Poradnik Językowy 5-6: 253-258.

Skorupka, Stanisław (1982): "Klasyfikacja jednostek frazeologicznych i jej zastosowanie w leksykografii". In: Basaj Mieczysław/Rytel, Danuta (ed.): Z problemów frazeologii polskiej i słowiańskiej I, Wrocław-Warszawa-Kraków-Gdańsk-Łódź, Ossolineum: 7-16.

Skorupka, Stanisław (1986): "Z zagadnień wariantu frazeologicznego". Prace Filologiczne XXXIII: 149-153.

Skorupka, Stanisław (1988): "Pojmowanie frazeologii w historii leksykografii polskiej". In: Basaj, Mieczysław/ Rytel, Danuta (ed.): Z problemów frazeologii polskiej i słowiańskiej IV. Wrocław usw., Ossolineum: 7-14.

Stein, Stephan (2011): "Formelhafte Texte oder textwertige Phraseologismen? Kontroverse Positionen, Empirische Beobachtungen, offene Fragen". In: Schäfer, Patrick/Schowalter Christine (ed.): In mediam linguam. Mediensprache - Redewendungen - Sprachvermittlung. Landau, Empirische Pädagogik: 161-176.

Stubbs, Michael (2001): Words and Phrases. Corpus Studies of Lexical Semantics. Oxford: Blackwell.

Taylor, John R. (2003): Cognitive Grammar. Oxford: Oxford University Press.

Wotjak, Barbara (1992): Verbale Phraseolexeme in System und Text. Tübingen: Niemeyer.

Żmigrodzki, Piotr (2003): Wprowadzenie do leksykografii polskiej. Katowice: Wydawnictwo Uniwersytetu Śląskiego.

\section{Wörterbücher}

Adalberg, Samuel (1894): Księga przysłów, przypowieści $i$ wyrażeń przysłowiowych polskich. Warszawa: Drukarnia Emila Skiwskiego.

Agricola, Johann (1529): Drey hundert Gemeyner Sprichwörter/der wir Deutschen uns gebrauchen und doch nicht wissen woher sie kommen. Haganow: Setzer.

Bąba, Stanisław/Dziamska, Gabriela/Liberek, Jarosław (1995): Podręczny słownik frazeologiczny języka polskiego. Warszawa: PWN.

Bąba, Stanisław/Liberek, Jarosław (1992): Mały słownik frazeologiczny współczesnego języka polskiego. Warszawa: Towarzystwo Miłośników Języka Polskiego.

Bąba, Stanisław/Liberek, Jarosław (2001): Słownik frazeologiczny współczesnej polszczyzny. Warszawa: PWN.

Dudenband 11 (1992) = Redewendungen und sprichwörtliche Redensarten. Mannheim usw.: Dudenverlag. 
Eiselein, Joseph (1840): Die Sprichwörter und Sinnreden des deutschen Volkes in alter und neuer Zeit. Freiburg: Wagner.

Friedrich, Wolf (1966): Moderne deutsche Idiomatik. München: Hueber.

Frisius, Johannes (1556): Dictionarium Latinogermanicum. Zürich.

Głowińska, Katarzyna (2000): Popularny stownik frazeologiczny. Warszawa: WILGA.

GWDS (1976-1981) = Das große Wörterbuch der deutschen Sprache. 1. Auflage. Mannheim: Bibliographisches Institut.

HDG $(1984)=$ Handwörterbuch der deutsche Gegenwartssprache. Berlin: Akademie.

Kłosińska, Anna/Sobol, Elżbieta/Stankiewicz, Anna (2005): Wielki słownik frazeologiczny PWN z przystowiami. Warszawa: PWN.

Krasnowolski, Antoni (1899): Słowniczek frazeologiczny. Poradnik dla piszacych. Warszawa: M. Arcta.

Mackensen, Lutz (1973): Zitate, Redensarten, Sprichwörter. Stuttgart: Fackelverlag.

Müldner-Nieckowski, Piotr (2003): Wielki słownik frazeologiczny języka polskiego. Warszawa: Świat Książki.

Röhrich, Lutz (1973): Das große Lexikon der sprichwörtlichen Redensarten. Freiburg i. B.: Herder.

Schelling, D./Emmel, H. (1586): Lexicon trilingue, Ex Thesauro Roberti Stephani, et Dictionario Ioannis Frisii summa FIDE Ac diligentia collectum [...]. Straßburg.

Schemann, Hans (1993): Deutsche Idiomatik: Die deutschen Redewendungen im Kontext. Dresden: Klett.

Schrader, Herman (1894): Der Bildschmuck der deutschen Sprache in Tausenden volkstümlicher Redensarten. Nach Ursprung und Bedeutung erklärt. Weimar: Felber.

Schulz, Dora/Griesbach, Heinz (1961): 1000 idiomatische Redensarten Deutsch. Berlin: Langenscheidt.

Skorupka, Stanisław (1967): Słownik frazeologiczny języka polskiego. Warszawa: Wiedza Powszechna.

Wander, Karl Friederich Wilhelm (1867): Deutsches Sprichwörterlexikon. Ein Hausschatz für das deutsche Volk. Leipzig: Brockhaus.

Wunderlich, Gottlob (1886): Deutsche Redensarten. Zur Pflege vaterländischer Sprachkenntnis in der Volksschule. 2. Auflage. Langensalza: Gressler. 